\title{
Article \\ Palladium Nanoparticles Functionalized with PVP-Quercetin Inhibits Cell Proliferation and Activates Apoptosis in Colorectal Cancer Cells
}

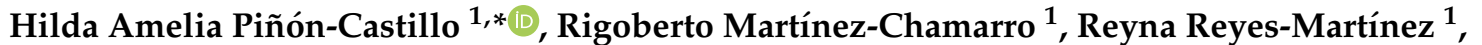 \\ Yarely M. Salinas-Vera ${ }^{2}$, Laura A. Manjarrez-Nevárez ${ }^{1}$, Laila Nayzzel Muñoz-Castellanos ${ }^{1}$ (D), \\ César López-Camarillo ${ }^{3}$ (D) and Erasmo Orrantia-Borunda ${ }^{4}$
}

1 Facultad de Ciencias Químicas, Universidad Autónoma de Chihuahua, Circuito Universitario S/N Campus II 1552, Chihuahua 31125, Mexico; a291813@uach.mx (R.M.-C.); rreyesm@uach.mx (R.R.-M.); lmanjarrez@uach.mx (L.A.M.-N.); lmunoz@uach.mx (L.N.M.-C.)

2 Departamento de Bioquímica, CINVESTAV-IPN, Av. Instituto Politecnico Nacional 2508, Ciudad de Mexico 07360, Mexico; yarely.salinas@cinvestav.mx

3 Posgrado en Ciencias Genómicas, Universidad Autónoma de la Ciudad de México, San Lorenzo 290, Ciudad de México 03100, Mexico; cesar.lopez@uacm.edu.mx

4 Centro de Investigación en Materiales Avanzados, S. C. Miguel de Cervantes 120, Complejo Industrial Chihuahua, Chihuahua 31136, Mexico; erasmo.orrantia@cimav.edu.mx

check for updates

Citation: Piñón-Castillo, H.A.; Martínez-Chamarro, R.;

Reyes-Martínez, R.; Salinas-Vera, Y.M.; Manjarrez-Nevárez, L.A.; Muñoz-Castellanos, L.N.;

López-Camarillo, C.;

\section{Orrantia-Borunda, E. Palladium}

Nanoparticles Functionalized with PVP-Quercetin Inhibits Cell Proliferation and Activates Apoptosis in Colorectal Cancer Cells. Appl. Sci. 2021, 11, 1988. https://doi.org/ 10.3390/app11051988

Academic Editor: Lionel Maurizi

Received: 16 January 2021

Accepted: 17 February 2021

Published: 24 February 2021

Publisher's Note: MDPI stays neutral with regard to jurisdictional claims in published maps and institutional affiliations.

Copyright: (c) 2021 by the authors. Licensee MDPI, Basel, Switzerland. This article is an open access article distributed under the terms and conditions of the Creative Commons Attribution (CC BY) license (https:// creativecommons.org/licenses/by/ $4.0 /)$.
* Correspondence: hpinon@uach.mx; Tel.: +52-614-236-6000

\begin{abstract}
Nanotechnology is focused on the development and application of novel nanomaterials with particular physicochemical properties. Palladium nanoparticles (PdNPs) have been used as antimicrobials, antifungals, and photochemicals and for catalytic activity in dye reduction. In the present investigation, we developed and characterized PdNPs as a carrier of quercetin and initiated a study of its effects in colorectal cancer cells. PdNPs were first functionalized with polyvinylpyrrolidone (PVP) and then coupled to quercetin (PdNPs-PVP-Q). Our results showed that quercetin was efficiently incorporated to PdNPs-PVP, as demonstrated using UV/Vis and FT-IR spectroscopy. Using transmission electron microscopy, we demonstrated a reduction in size from 3-14.47 nm of PdNPs alone to 1.8-7.4 nm of PdNPs-PVP and to 2.12-3.14 of PdNPs-PVP-Q, indicating an increase in superficial area in functionalized PdNPs-Q. Moreover, hydrodynamic size studies using dynamic light scattering showed a reduction in size from $2120.33 \mathrm{~nm} \pm 112.53$ with PdNPs alone to $129.96 \mathrm{~nm} \pm 6.23$ for PdNPs-PVP-Q, suggesting a major reactivity when quercetin is coupled to nanoparticles. X-ray diffraction assays show that the addition of PVP or quercetin to PdNPs does not influence the crystallinity state. Catalytic activity assays of PdNPs-PVP-Q evidenced the chemical reduction of 4-nitrophenol, methyl orange, and methyl blue, thus confirming an electron acceptor capacity of nanoparticles. Finally, biological activity studies using MTT assays showed a significant inhibition $(p<0.05)$ of cell proliferation of HCT-15 colorectal cancer cells exposed to PdNPs-PVP-Q in comparison to untreated cells. Moreover, treatment with PdNPs-PVP-Q resulted in the apoptosis activation of HCT-15 cells. In conclusion, here we show for the first time the development of PdNPsPVP-Q and evidence its biological activities through the inhibition of cell proliferation and apoptosis activation in colorectal cancer cells in vitro.
\end{abstract}

Keywords: palladium nanoparticles; polyvinylpyrrolidone; quercetin; colorectal cancer; apoptosis

\section{Introduction}

Nanotechnology has become a very wide and diverse research area with rapid development and application. An objective of nanotechnology study is nanoparticles (NPs) with different compositions. Metallic nanoparticles have been of great interest due to their specific physicochemical characteristics. These characteristics include a small size (between 1-100 nm), a large superficial area, high reactivity, and the extraordinary quantum 
effect [1,2]. Due to their physical-chemical characteristics, NPs have incredible pharmacokinetic properties and can be used as carriers of drugs or molecules for a specific purpose (antibiotics, antibodies, or organic molecules) [3,4]. However, nanoparticle stability remains challenging, due to the electrostatic attraction in naked NPs, which tend to agglomerate. PdNPs superficial modification to avoid agglomeration has been reported [5,6]. Molecules as glucosamine [7], sodium dodecyl sulfate (SDS) [8,9], tween [10], and PEG [5,6,11] have been used to superficially modified the NPs. The mechanisms reported to avoid agglomeration were the addition of negative charges to NP surfaces, which increases the repulsion forces inhibiting the union of several NPs [12], and molecule additions to surface NPs generate a steric stabilization [13]. Palladium nanoparticles (PdNPs) have been added to carbon nanofibers using SDS as a surfactant. The ends of SDS bind to palladium ions and the fast ion reduction suppresses the agglomeration of PdNPs [14]. Palladium is a platinum group element (PEG). In this group, it is possible to find the platinum derivate cisplatin, a metal-based drug used in cancer therapy. Nevertheless, cancer therapy with platinum showed high secondary effects, and many cancer types have developed resistance to it. In this respect, the palladium complex derivate and PdNPs show promising antitumor activity. A few PdNP antitumor effects have been reported. PdNPs were used in a transferrin platform, loaded with paclitaxel, and used to study inhibitory effects in an MCF-7 cellular line. The results showed that a combination of PdNP and paclitaxel in polymeric nanoparticles increased cytotoxicity more than PdNPs or paclitaxel alone. The use of lasers increased cytotoxicity activity [15]. Phan et al. [16] synthesized PdNP coatings with chitosan, which showed a 20\% inhibition in MDA-MB-231 cells when irradiated with infrared light. Moreover, PdNPs have been used for bacterial [17] or fungal inhibition [18], showing effective inhibition. Different PdNP synthesis methods have been validated. The use of such plant extracts as Ananas comosus [19], Spirulina platensis [20], and Sapium sebiferum [21], among other reducing agents, have shown that metabolites from natural sources can be used as reducing and stabilizing agents. The presence of proteins and phytochemicals such as steroids, flavonoids, alkaloids, and other molecules in these extracts favors metal reduction and nanoparticle stability $[22,23]$. The activity shown in these nanoparticles can be mediated by the functional groups adhering to the PdNP surface. Among the molecules adhering to the NP superficies are flavonoids. Flavonoids are molecules that show important antioxidant (activating enzymes involved in oxidative stress response), antitumor, and anti-inflammatory activity. Anti-inflammatory activity inhibits cytokine production, among other activities [24]. It has been reported that this flavonoid affects cell proliferation in different cancer cell line types $[25,26]$. One of the most studied flavonoids is quercetin due to its antioxidant, anti-inflammatory, and antiproliferative effects [27]. Quercetin is the most abundant flavonoid and is ubiquitously distributed in plants. Dietary sources of quercetin include apples, strawberries, onion, tea, and wine [28]. Moreover, the role of quercetin in iron regulation through inhibiting lipid oxidation and reducing iron valence is well described [29]. It has been stated that quercetin inhibits cell proliferation and triggers apoptosis by deregulating the genes Bax and Bcl-2, and this generates an arrested cell cycle at G2/M phases in glioblastoma U251 cells [30]. It was reported that in metastatic ovarian cancer cells, quercetin increases the level of proapoptotic molecules such as cytochrome c, Bid, Bad, Bax, caspase-3, and caspase-9, indicating the mitochondrialmediated apoptotic pathway [31]. Similar results have been described in prostate cancer; quercetin activates caspase- 3 and caspase- 9 triggering apoptotic mechanisms via the mitochondrial pathway [32].The NPs used as carriers for the delivery of quercetin into target cells have been evaluated in different diseases $[33,34]$. On the one hand, NPs alone offers a system that causes damage to specific cells by mechanisms such as oxidative stress, lipids and proteins oxidation, and high toxicity due to their physicochemical characteristic as the superficial charge [35]. In some cases, like cancer, central nervous degenerative, and cardiovascular diseases damage is generated by oxidative stress [36]. Two strategies to respond to oxidative stress have been described: (i) endogenous detoxifying systems including the enzymatic activities such as superoxide dismutase (SOD), catalase (CAT), and 
glutathione peroxidase (GPx) and (ii) nonenzymatic activity of exogenous molecules such as quercetin, vitamin $\mathrm{C}$, and lycopene which also show potent antioxidant activities [34]. However, the exogenous antioxidant molecules are light, temperature and $\mathrm{pH}$ sensible, and enzymatic degradation susceptible [36]. An efficient form to inhibit this degradation is the encapsulation or transportation of these molecules by organic or metallic nanoparticles [36]. Gold NPs have been used as quercetin carriers, the NPs inhibit epithelial-mesenchymal transition, angiogenesis, and metastasis in breast cancer cell lines [37]. Quercetin has been encapsulated in a self-assembled chitosan system. The system proved to be efficient in the inhibition of breast cancer cell proliferation [38]. Metallics and organic nanoparticles coupled to quercetin have been also proved to be useful in the inhibition of oxidative stress in degenerative diseases [37,39]. Ultrasmall bimetallic Cu2-xSe-based bimetallic nanoparticles modified with quercetin promoted the microglia polarization and downregulate IL-6 and upregulate IL-10 playing anti-inflammatory activity [34]. However, as was describe before, PdNPs play an important role in nanomedicine and nanobiology due to their activity against a broad spectrum of organisms, and their chemical properties make the PdNPs a desirable candidate for the functionalization with quercetin.

Previously, we have developed PdNPs and tested their effects as a fungicide, showing that treatments induce cell wall damage and oxidative stress in Aspergillus niger and Candida albicans [18]. Here, we extend these initial findings in fungus; we functionalized PdNPs with PVP (PdNPs-PVP) and with quercetin (PdNPs-PVP-Q). The physicochemical characteristics were evaluated, and their biological activity was tested in colorectal adenocarcinoma HCT-15 cells, as quercetin is a well-known antitumor naturally occurring agent. Although several studies have reported the anti-tumor effects of quercetin in HCT-15 cancer cells, no previous approaches using palladium nanoparticles coupled with quercetin to deliver cargo into colon cancer cells have been reported.

\section{Materials and Methods}

\subsection{Materials and Cells}

All chemicals used for the NP synthesis and functionalization were reactive grade. Potassium palladium (II) chloride (CAS number 10025-98-6), sodium tetrahydroborate (CAS number 16940-66-2), polyvinylpyrrolidone (CAS number 9003-39-8), quercetin (CAS number 849061-97-8), methylene blue (CAS number 122965-43-9), methyl orange (CAS number 547-58-0), and 4-nitrophenol (CAS 100-02-7) were supplied by Sigma-Aldrich (St. Louis, MO, USA). HCT-15 colorectal cancer cells (ATCC-CCL-225) were purchased from ATCC and were grown in Dulbecco's Modified Eagle Medium (DMEM) culture media at $37^{\circ} \mathrm{C}$ in a $5 \% \mathrm{CO}_{2}$ atmosphere.

\subsection{Nanoparticles Synthesis}

The PdNPs, PdNPs-PVP, and PdNPs-PVP-Q were synthesized using the reduction method described by Creighton and Eadont [40] with some modifications. The modifications were made in a reaction of $\mathrm{K}_{2} \mathrm{PdCl}_{4}(1 \mathrm{mM})$ with $\mathrm{NaBH}_{4}(3 \mathrm{mM})$. PVP was added in a final proportion of $5 \%(\mathrm{p} / \mathrm{v})$. The reaction was stirred for $24 \mathrm{~h}$ at room temperature. Afterward, PVP-PdNPs were centrifuged for $20 \mathrm{~min}$ at 37,567 RCF. They were washed with distilled water twice and left to dry at $60^{\circ} \mathrm{C}$. The PVP-PdNPs were used for quercetin functionalization. A known weight of PVP-PdNPs was suspended in water and mixed with a quercetin solution in a $2 \%$ final concentration $(\mathrm{p} / \mathrm{v})$. The suspension was then agitated $12 \mathrm{~h}$ in light absence. PdNPs-PVP-Q were recovered by centrifugation and characterized. The synthesis of all nanoparticles was monitored by a UV/visible spectrophotometer in a range from 200 to $1100 \mathrm{~nm}$ (Evolution 220 Thermo Scientific).

\subsection{Nanoparticles Characterization}

The size, morphology, and agglomeration of all nanoparticles were analyzed by electronic microscopy. All the samples were suspended in ethanol, and the suspensions were then sonicated for $30 \mathrm{~min}$ using a bath sonicator (Cole-Parmer). Afterward, the 
samples were placed in an aluminum support for Scanning Electron Microscopy (JEOL JSM model 7401F) and carbon-coated copper grid for Transmission Scanning Microscopy (JEOL model TEM-2100F). An average of 300 nanoparticles was counted to obtain the distribution size. The hydrodynamic size and zeta potential were determined in a Malvern Zetaziser Nano ZS instrument operating at a light source wavelength of $532 \mathrm{~nm}$, and a fixed scattering angle of $173^{\circ}$ was used. A flow rate of $0.5 \mathrm{~mL} / \mathrm{min}$ was used, and dynamic light scattering was analyzed every $3 \mathrm{~s}$. Zeta potential was determined with laser Doppler electrophoresis using the same equipment. Changes in structure and confirmation of PVP and quercetin addition were measured via X-ray diffraction and FTIR-IR analysis. The crystallinity structure of all synthesized NPs was determined in an X-ray diffractometer model XDR, DP Phillips Xpert PRO, with $\mathrm{Cu}-\mathrm{K} \alpha$ radiation $(\lambda=0.15406 \mathrm{~nm})$ in a $2 \theta$ range from $20^{\circ}$ to $80^{\circ}$. FTIR-IR analysis was done in a range from 399 to $3999 \mathrm{~cm}-1$ in a FTIR-IR Afinnity-1S spectrophotometer (Shimadzu).

\subsection{Nanoparticles Reactivity Characterization}

\subsubsection{Dye Degradation}

All nanoparticles were employed to evaluate their degradation dye evaluation. The dyes employed were methylene blue (MB), methyl orange (MO), and 4-nitrophenol (4N; all at $10 \mu \mathrm{M})$ with sodium borohydride $\left(\mathrm{NaBH}_{4} ; 5 \mathrm{mM}\right)$. All dyes were exposed to NPs at $10 \mathrm{ppm}$ and were incubated in the dark for $60 \mathrm{~min}$. After that, the absorbance in a UV-visible spectrum was measured from 300 to $800 \mathrm{~nm}$ (Varioskan Lux Thermo Scientific, Waltham, MA, USA).

\subsubsection{Quercetin Liberation}

The nanoparticles were suspended in a phosphate buffer, collocated in a dialysis membrane (repligen ${ }^{\circledR} \mathrm{MWCO}, 300 \mathrm{Kd}$ ), and stirred for $24 \mathrm{~h}$ at $4{ }^{\circ} \mathrm{C}$ at a pH of 6.5 and 7.0. Samples were taken at 12 and $24 \mathrm{~h}$ for quercetin determination. The quercetin concentration was determined in a UV-visible spectrum (Varioskan Lux Thermo Scientific, Waltham, MA, USA), using quercetin as the standard curve.

\subsection{Cellular Activity}

\subsubsection{Cell Proliferation Assays}

HCT-15 cells were plated at a density of $1 \times 10^{4}$ cells/well into 96-well dishes in a complete medium. The HC-T15 cells were treated with PdNPs, PdNPs-PVP, and PdNPsPVP-Q at $1000 \mathrm{ppm}$ for 0 and $36 \mathrm{~h}$. For cell proliferation analysis, the MTT reagent ([3-[4,5-dimethylthiazol-2-yl]-2,5 diphenyltetrazolium bromide] was added to HCT-15 cells $\left(1 \times 10^{4}\right)$ and incubated for $3 \mathrm{~h}$ at $37^{\circ} \mathrm{C}$. Afterward, isopropanol was added to the cells, and the cells were incubated for $10 \mathrm{~min}$. Absorbance was recorded at different time points using a spectrophotometer (model Evolution 220; Thermo Scientific, $570 \mathrm{~nm}$ ). Assays were performed three times, and data were expressed as mean \pm standard deviation (SD).

\subsubsection{Apoptosis Assays}

Death of the HCT-15 colorectal cancer cells was quantified by fluorescence-activated cell sorting (FACS) assays using the annexin $\mathrm{V}$ method. An annexin-V/propidium iodide (PI) double assay was performed using the apoptosis detection kit (Roche). For assays, HCT-15 cancer cells were treated with PdNPs, PdNPs-PVP, and PdNPs-PVP-Q at 1000 ppm and were then incubated at $37^{\circ} \mathrm{C}$ in a $5 \% \mathrm{CO}_{2}$ atmosphere for $36 \mathrm{~h}$. Cells were detached and resuspended in $100 \mu \mathrm{L}$ of incubation buffer with $2 \mu \mathrm{L}$ of Annexin and $2 \mu \mathrm{L}$ of propidium iodide according to the manufacturer's recommendations. Stained cells were analyzed in a FACSCALIBUR flow cytometer (BD Biosciences). Quercetin and cisplatin controls were added at 40 and $50 \mu \mathrm{M}$ concentrations, respectively. The assays were repeated three times, and data were expressed as mean \pm standard deviation (SD). Statistical analyses were performed using a Student's $t$-test, and a $p$-value $<0.05$ was considered significant. 


\subsection{Statistical Analysis}

Experiments were performed three times in triplicate, and results were expressed as mean \pm standard deviation (SD). A $p<0.05$ value was considered statistically significant.

\section{Results and Discussion}

\subsection{Nanoparticles Synthesis}

Due to their physicochemical activity, NPs have been proposed as carriers of drugs, biological molecules, and antibodies. In our previous work, PdNPs demonstrated antifungal activity [18]. In this work, we added PVP to the PdNP synthesis as a surfactant to modify their surface, and this worked as a link between quercetin and PdNPs. PdNP modification by PVP and the further addition of quercetin were evaluated by UV/Vis spectrometry (Figure 1). The reaction showed a color change from yellow-orange to brown dark, indicating Pd ion reduction. These color changes have been reported in other works [41,42]. $\mathrm{UV} /$ vis spectrometry analysis showed peaks of absorption in a range from 199 to $414 \mathrm{~nm}$ in the PdNPs-PVP-Q, suggesting incorporation of both components in the PdNPs system (Figure 1). These results are consistent with the green synthesized PdNPs mediated by carboxymethylcellulose [41] and an extract from Euphorbia granulate [43].

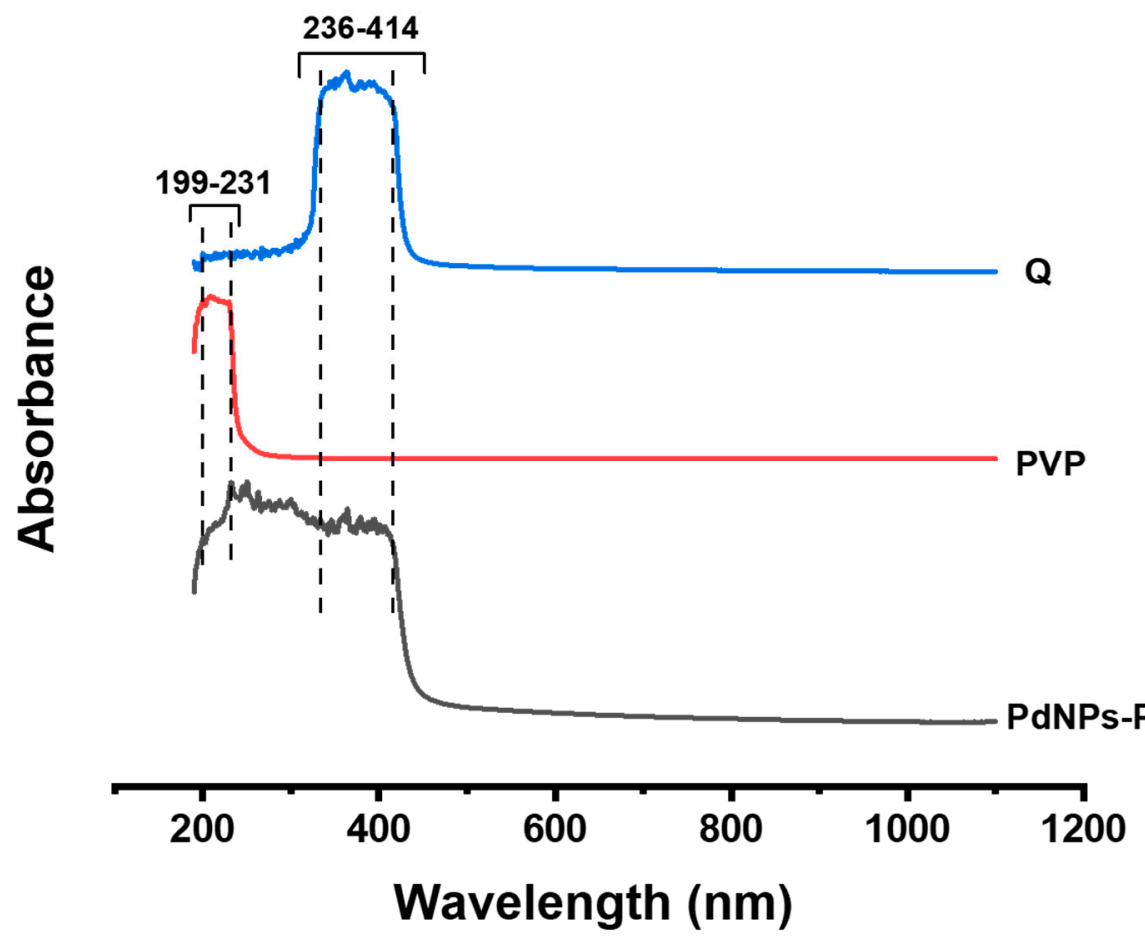

Figure 1. Nanoparticles UV/visible analysis. The absorbance was shown for all the components involved in the functionalization $\quad$ quercetin $(\mathrm{Q}), \mathrm{w}$ polyvinylpyrrolidone (PVP), $\square$ Palladium nanoparticles (PdNPs)-PVP-Q.

\subsection{Nanoparticle Characterization}

Scanning and transmission electron microscopy (SEM and TEM, respectively) were used to characterize NP size and morphology. The SEM micrographs showed a spherical nanoparticle with a size of approximately $5 \mathrm{~nm}$ without the surfactant and quercetin (Figure 2a). When the PVP and the quercetin were added to the reaction, an envelope was observed (Figure 2b,c). Agglomeration in PdNP synthesis with PVP has been shown [44,45]. However, Çelik et al. [46] showed a palladium cobalt nanoparticle synthesized with PVP without agglomeration. Agglomeration could be attributed to PdNP synthesis, because, in this experiment, a reduction method synthesis was used. The influence of method synthesis in size and morphology has been shown in previous works $[47,48]$. 

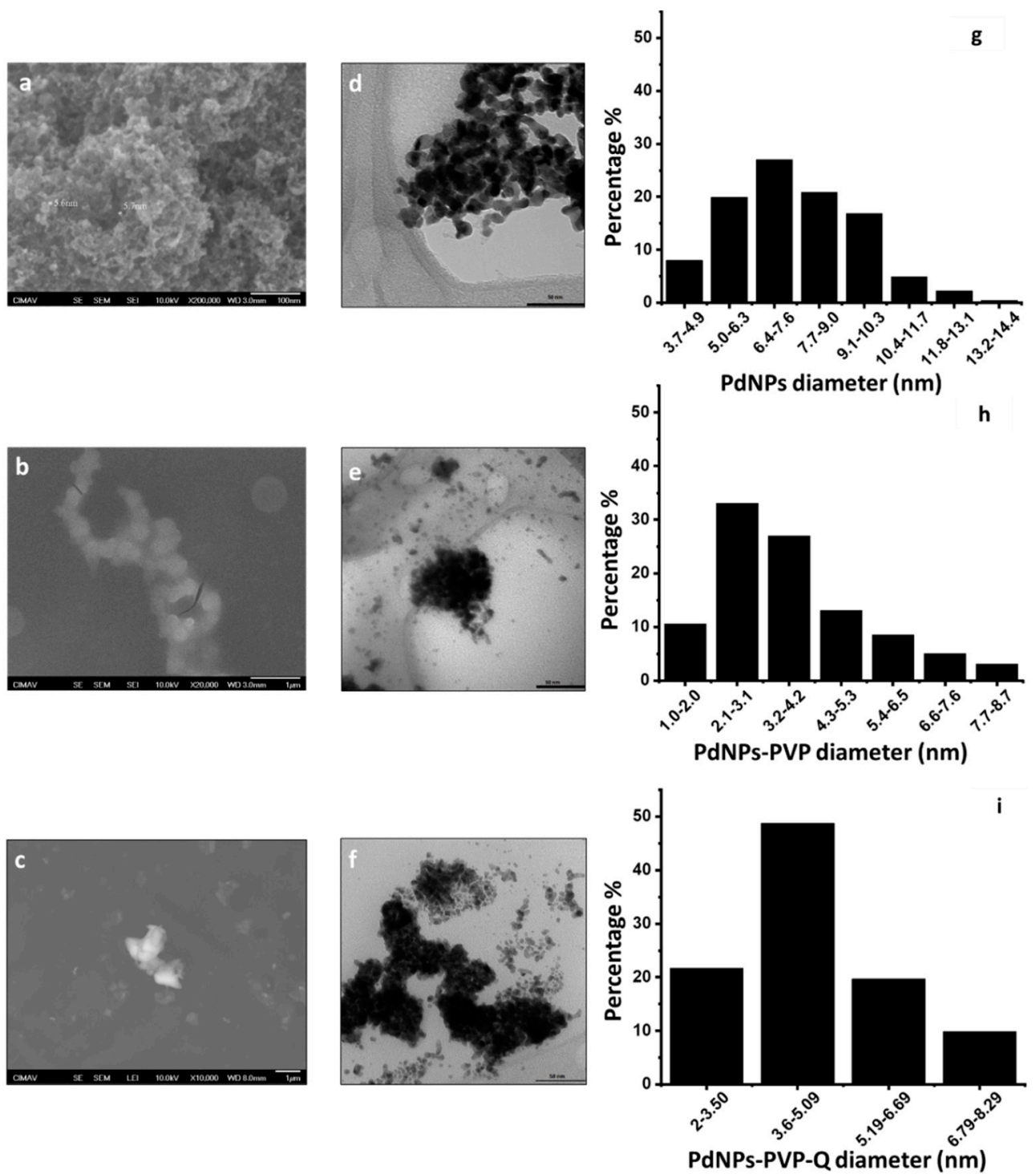

Figure 2. Characterization of size and morphology by electron microscopy. (a-c) Scanning electron microscopy: (a). PdNPs alone, (b). PdNP-PVP, and (c). PdNP-PVP-Q. (d-f) Transmission electron microscopy: (d). PdNPs alone, (e). PdNP-PVP, and (f). PdNP-PVP-Q. (g-i). Distribution analysis of primary size: (g). PdNPs alone, (h). PdNP-PVP, and (i). PdNP-PVP-Q. The white and black lines represent the scale in every micrograph in a-f.

The TEM analysis showed that the nanoparticles have a semispherical shape regardless of the PdNP type evaluated (Figure 2a-f). Similar results were found with the reduction of palladium chloride by tetraethylene glycol with $\mathrm{KOH}$ [45] and with reduction mediated by heat and the use of carboxymethylcellulose [41]. Nevertheless, other authors have reported PdNP synthesis as spherical, using methanol as a reducing agent [47], square-shaped, with citric acid as a reduction agent, heat, and PVP as a stabilizing agent [49], and flower-shaped and porous [16].

TEM analysis showed the differences in size with the PVP and quercetin addition (Figure 2g-i). The PdNPs alone showed a size between 3.7 and $14.47 \mathrm{~nm}$, with almost 30\% of PdNPs in a range from 6.42 to $7.42 \mathrm{~nm}$ (Figure 2g). The surfactant addition produces nanoparticles with a size range between 1 and $8.74 \mathrm{~nm}$, with 35\% of PdNPs in a size from 2.12 to $3.14 \mathrm{~nm}$ (Figure 2h). When the quercetin was added to PdNPs-PVP, the nanoparticles showed a tighter distribution from 2.3 to $8.29 \mathrm{~nm}$ (Figure 2i). Additionally, the PdNPs-PVP-Q showed 50\% of PdNPs in a size range from 3.6 to $5.09 \mathrm{~nm}$ (Figure 2i). Quercetin helps nanoparticles to have a more uniform size, even more so the surfactant (PVP). Change in the distribution size could be attributed to the addition of quercetin on 
the PdNPs-PVP surface, which avoids nucleation and increases in size. It has been reported that NP size decreased when surfactant was added to the nanoparticle synthesis due to the NPs' stabilization $[48,50][49,51,52]$. This stabilization depends on the molecule size employed, the charge, and the molecule's nature [9,12]. Regarding NP synthesis mediated by an extract from plants, it was suggested that the reduction of metallic salts could be carried out by flavonoid molecules such as apigenin and luteolin [51]. Additionally, these molecules and phenols provide stability in the nanoparticle formed [52,53].

Nanoparticles agglomerate in a solution depending on the solution's ionic strength and the nanoparticles' superficial charge [54]. Because of this, determining the size of the nanoparticles in suspension is important. To determine these nanoparticle characteristics, hydrodynamic size and zeta potential were analyzed (Figure 3). In each part of the NP synthesis, the addition of PVP or quercetin changes the hydrodynamic size and zeta potential (Figure $3 a$ and $3 b$, respectively). Hydrodynamic size showed a diminution depending on the NP type (Figure 3a). This diminution showed an exponential correlation between the type and the hydrodynamic size form $\left(R^{2}=0.999\right.$; Figure 3a). PdNPs alone showed a size $2120.33 \pm 112.53 \mathrm{~nm}$, three times larger than PdNPs-PVP and 16 times larger than PdNPs-PVP-Q (Figure 3a). The size diminution with PVP addition in silver nanoparticles [55], antimony [56], or bismuth [57] has been shown. Surfactant and quercetin addition generated a diminution in size and zeta potential.

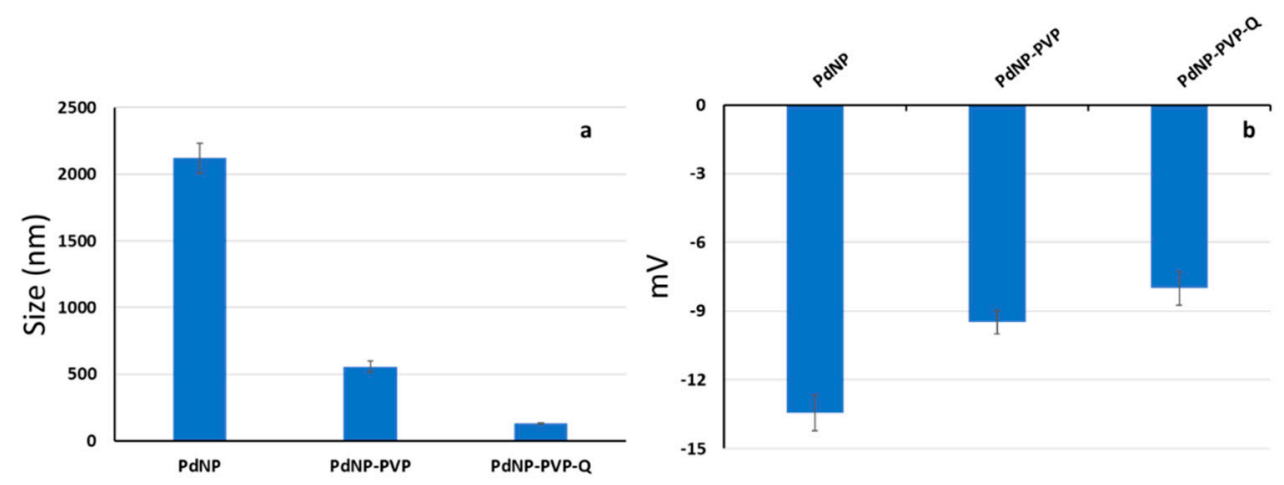

Figure 3. Hydrodynamic size and potential zeta characterization. (a). Hydrodynamic size determination. (b). Potential zeta size determination. Both were determined in bidistilled water with a concentration of 300 ppm for each nanoparticle.

The index of the interaction between colloidal nanoparticles is estimated by the zeta potential. Thus, this parameter measures the nanoparticles' capacity to agglomerate or its dispersion stability. Nanoparticles with a zeta potential larger than $+30 \mathrm{mV}$ or $-30 \mathrm{mV}$ normally are considered stable [55]. The addition of PVP or PVP-Q addition to PdNPs showed a change in the zeta potential (Figure 3b). PdNPs-PVP-Q showed the smallest value with a charge of $-7.9 \pm 0.73 \mathrm{mV}$. In both attributes (hydrodynamic size and zeta potential), the quercetin contributes to the size of nanoparticles favorably. These results are coincident with the result shown by Vergara-Castañeda et al. [58]. However, this result is not consistent with the zeta potential increase from $\mathrm{Sb}_{2} \mathrm{~S}_{3}$ [56] or $\mathrm{Bi}_{2} \mathrm{~S}_{3} \mathrm{NPs}$ [57], where the increase was related to the hydrodynamic size diminution. Two mechanisms have been reported for NP stabilization: (1) electrostatic stabilization, where the nanoparticles are repelled by the NPs' surface charge, and (2) steric stabilization, where NPs are coated by macromolecules, which generates repelling forces $[13,50]$.

X-ray diffraction analysis was performed to describe the crystallinity of the nanoparticles (Figure 4). PdNPs showed a centered cubic structure (fcc) with five pics at 40.1, 46.4, 67.9, 82.7, and 86.7 2-tetha, indicating the presence of (111), (200), (220), (311), and (222) planes. The PVP and quercetin addition in the nanoparticles caused a diminution in intensity compared to PdNPs alone (Figure $4 b, c)$. However, such an addition does not change the NPs' crystallinity. Previous studies have reported that the addition of PVP to PdNPs showed no change in the NPs' crystallinity, only in the intensity [59]. 

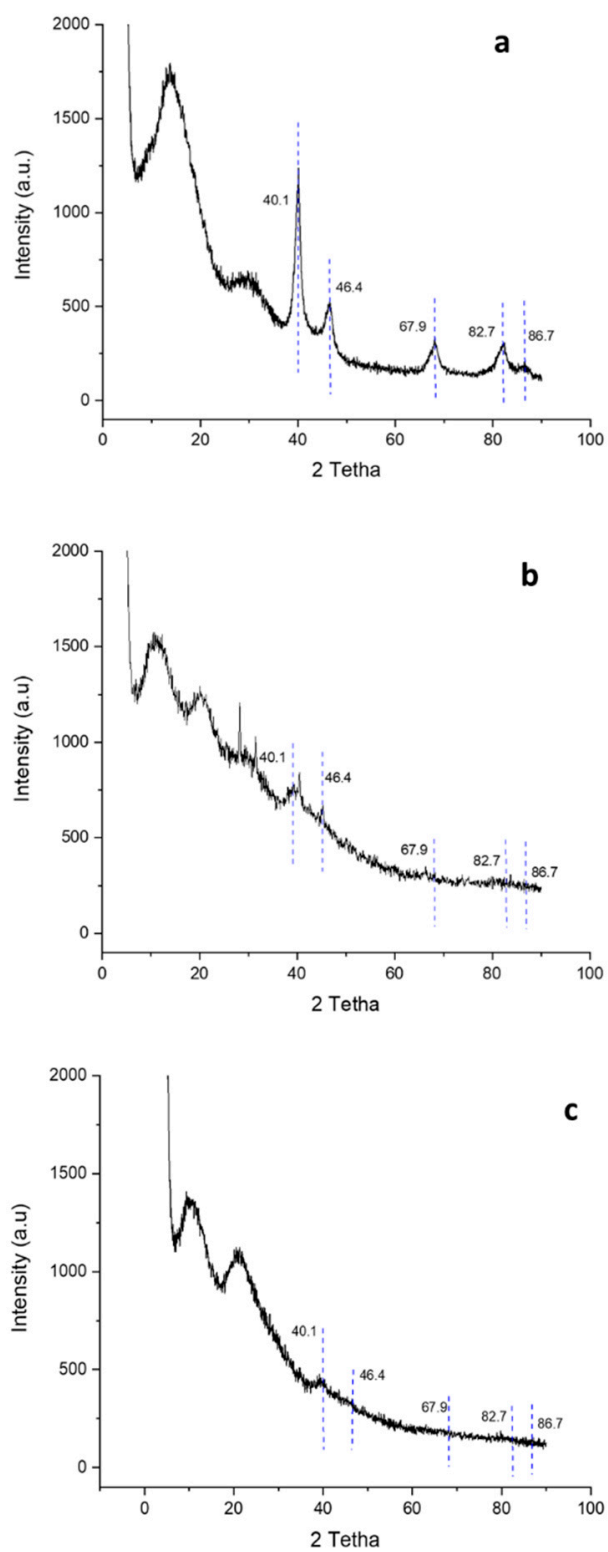

Figure 4. X-ray diffraction of PdNPs synthetized alone (a), with PVP (b), or with PVP-Q (c).

To further confirm the incorporation of quercetin with PdNPs, we used FT-IR spectroscopy (Figure 5). Our results indicated that quercetin showed characteristic transmittance bands. The $\mathrm{OH}$ group stretching was detectable at 3406 and $3283 \mathrm{~cm}^{-1}$, while the $\mathrm{OH}$ bounded to the phenol group was detected at $1379 \mathrm{~cm}^{-1}$. The aryl group was detectable at $1666 \mathrm{~cm}^{-1}$, and the $\mathrm{C}=\mathrm{C}$ from the aromatic ring was found at 1610,1560 , and $1510 \mathrm{~cm}^{-1}$. The C-H in aromatic hydrocarbon in the plane was detectable at $1317 \mathrm{~cm}^{-1}$, whereas the $\mathrm{C}-\mathrm{H}$ out of the plane was observed at $933,820,679$, and $600 \mathrm{~cm}^{-1}$. The C-O stretch in the aryl ether group was observed at $1263 \mathrm{~cm}^{-1}$, while C-O stretching in the phenol was observed at $1200 \mathrm{~cm}^{-1}$, and the C-CO-C stretch in ketone was observed in $1165 \mathrm{~cm}^{-1}$ which has been reported as a band typical of quercetin [60]. 


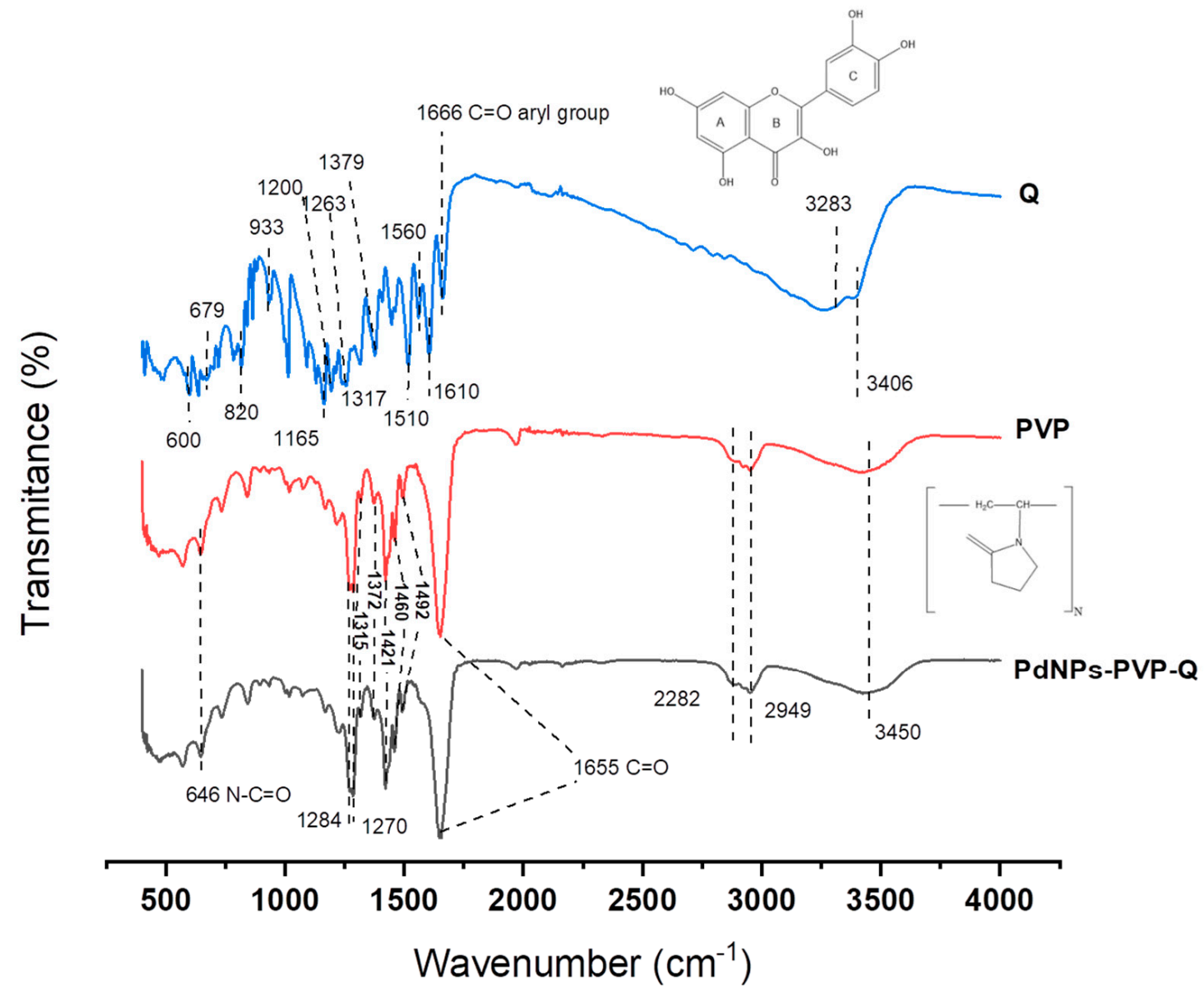

Figure 5. Fourier transformed infrared spectroscopy (FT-IR). The transmittance is shown for all components involved in functionalization $\mathrm{Q}, \mathrm{PVP}, \mathrm{PdNPs-PVP-Q}$.

The PVP characteristic bands in the $1655 \mathrm{~cm}^{-1}$ correspond to the $\mathrm{C}=\mathrm{O}$ group. The bands stretching at 1492,1460 , and $1421 \mathrm{~nm}$ correspond to $\mathrm{CH}_{2}$ deformation, the $1372 \mathrm{~cm}^{-1}$ band corresponds to $\mathrm{CH}$ deformation and $646 \mathrm{~N}-\mathrm{C}=\mathrm{O}$ bands [61]. Quercetin used to load $\mathrm{ZnO}$ with PBA as a surfactant showed the successful load of quercetin into NPs [62]. Additionally, quercetin has been used to load silica NPs without the addition of surfactants, indicating the possibility of quercetin union without an intermediate [58]. The interaction of quercetin with the PVP could be mediated by hydrogen bonds between the $\mathrm{OH}$ from quercetin and the $\mathrm{O}$ and $\mathrm{NH}$ from PVP.

\subsection{Nanoparticles Reactivity Characterization}

PdNPs promises to be useful as catalysts in various reaction types as a Suzuki's reaction [63] or dye degradation [7]. This characteristic is important since it shows their reactivity in an environment that surrounds them. PdNPs works as an electron acceptor in the presence of $\mathrm{H}_{2}$ in a catalytic reaction [64]. These reaction mechanisms could be involved in the toxicity mechanisms with different cell types. It has been explained that a Fenton-type reaction is involved in the toxicity mechanism of NPs. This catalytic reaction has also been used in organic pollutant degradation [65]. As a part of PdNPsPVP-Q characterization, dye degradation was evaluated (Figure 6). The PdNPs-PVP-Q showed catalytic activity in the MO and $4 \mathrm{~N}$ (Figure $6 \mathrm{a}, \mathrm{b}$, respectively) but not in MB. The decolorization changes were observed immediately after $\mathrm{Na}_{2} \mathrm{BH}_{4}$ addition. The degradation of $4 \mathrm{~N}$ has been reported by PdNPs synthesized using protein ferritin from Pyrococcus furios as a stabilizer [66]. The degradation of MB at a low rate due to a large kinetic energy barrier has been reported [52]. Many factors influence MB degradation, such as $\mathrm{pH}$ and the presence of amine groups [67]. Additionally, the photolytic activity 
degradation of MB by PdNPs has been demonstrated [7]. Dye water contamination is an important pollution problem [68], and NPs represent an alternative to a solution to this. Different NPs used for wastewater have been used as an alternative for dye degradation $[68,69]$.
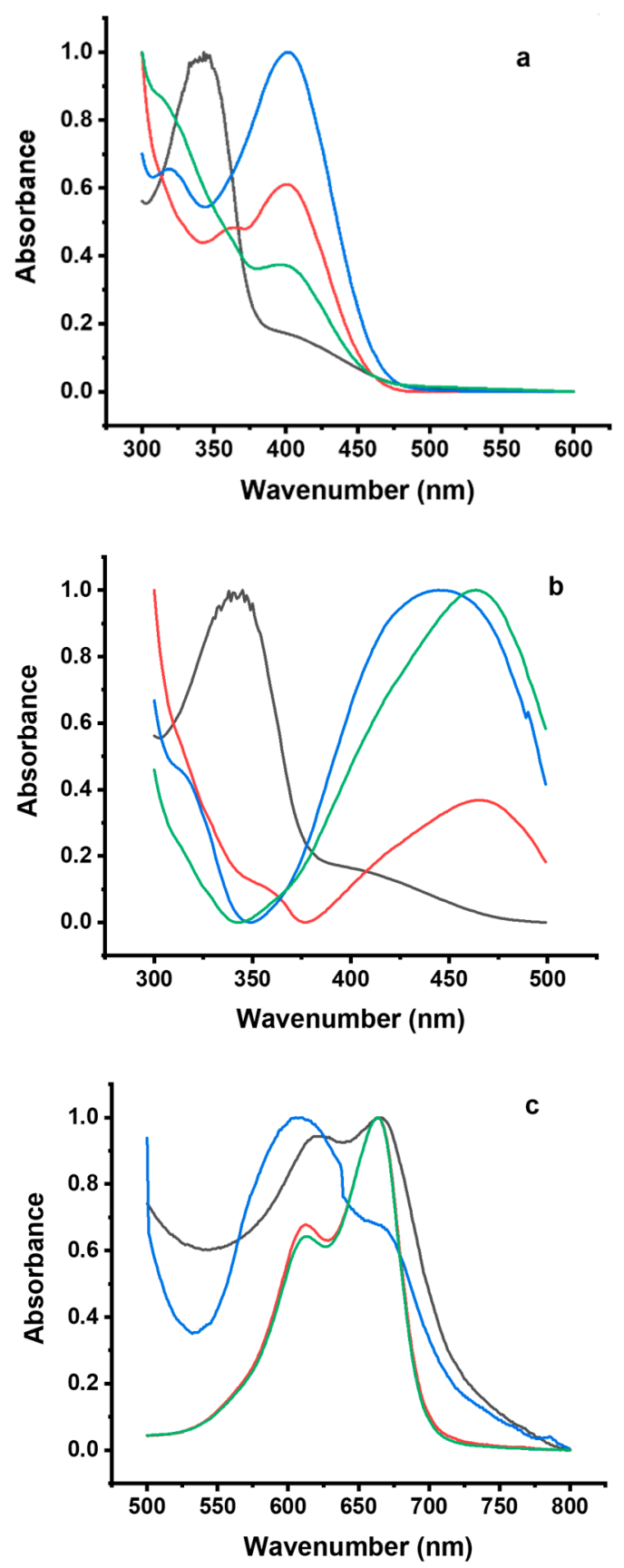

Figure 6. PdNPs-PVP-Q Catalytic activity. (a). 4-nitrophenol, (b). methyl orange, and (c). methyl blue. The components involved in functionalization: quercetin, $=$ PVP, 2 PdNPs-PVP-Q, dye.

\section{Quercetin Liberation}

The capacity of nanoparticles as carriers has been widely reported [70,71]. In this work, we studied the ability of NPs to release quercetin at different $\mathrm{pH}$ levels (Figure 7). PdNPs-Q and PdNPs-PVP-Q were employed (orange and gray bars in Figure 7, respectively). Both nanoparticles were effective in quercetin liberation, but PdNPs-PVP were the most efficient. 
$\mathrm{pH}$ was shown to affect this liberation. No influence of time was observed. The quercetin concentration was the same at 6 and $12 \mathrm{~h}$ (Figure 8A,B). However, $\mathrm{pH} 7.5$ allowed for the liberation of almost twice the concentration of quercetin than at $\mathrm{pH} 6.5$ (Figure 8B). $\mathrm{pH}$ influence in molecule liberation from NPs has been shown before [11,15]. Rhodamine B liberation of silica-alginate nanoparticles was more efficient at a $\mathrm{pH}$ of 7.5 than 2.5 [72]. Quercetin has been used as a load molecule for ZnONPs; however, in these nanoparticles, more efficient quercetin liberation was presented at a $\mathrm{pH}$ of 6.5 [62]. In contrast, Akal et al. [73] showed that in silica, NPs loaded with folic acid and quercetin, a pH of 4.4 was more efficient for quercetin liberation.

\subsection{Effects of PdNPs-PVP-Q on the Cell Viability and Apoptosis of Cancer Colorectal Cells}

A colorectal adenocarcinoma HCT-15 cell line was employed to evaluate the capacity of PdNPS-PVP-Q to inhibit cell proliferation. After $36 \mathrm{~h}$ of incubation, PdNPs-PVP and PdNPs-PVP-Q treatments resulted in a significant cell growth inhibition in comparison with the untreated control. Differences between both PdNPs-PVP and PdNPs-PVP-Q treatments were found $(p<0.05$; Figure $8 \mathrm{~A})$. Afterward, the apoptotic percentage of cells exposed to PdNPs-PVP and PdNPs-PVP-Q was evaluated. The exposure of HCT-15 cells to PdNPs-PVP did not result in significant differences in cell death in comparison to the untreated control. In contrast, the incubation of cells with PdNPs-PVP-Q resulted in a slight but significant $(p<0.05)$ increase in apoptosis (Figure 8B). As a control, we used quercetin $(40 \mu \mathrm{M})$ alone and observed a considerable increase in cell death, as has been reported [74]. Additionally, as a positive control of cell death, we used cisplatin $(50 \mu \mathrm{M})$, which induced extensive cell death, as expected. It has been proved that PdNPs generate oxidative stress, induce mitochondrial dysfunction, and induce apoptosis increasing caspase 3 in SKOV3 cells [75]. Additionally, porous palladium transferrin-conjugated nanoparticles have been reported to be effective in chemo-phototherapy with regard to MC-7 human breast adenocarcinoma cell lines [15]. Concave PdNPs have been used with ascorbate for the inhibition of colorectal adenocarcinoma cell viability. The addition of concave PdNPs to the ascorbate promoted dose-dependent PdNP toxicity and increased ascorbate activity [76]. Quercetin has been reported as a very potent antioxidant molecule [77] and as a chemosensitizer and cancer chemotherapy [78]. Quercetin triggers apoptotic mechanisms as a growth control of colorectal cancer [15]. Our data showed that PdNPs-PVP-Q induces a small increase (8\%) in apoptosis relative to control. This slight effect may be due to (i) the low effective concentration of quercetin delivered in the cellular cytoplasm, (ii) the effect of temperature in the release of quercetin from PdNPs in the cellular microenvironment, and (iii) the potential agglomeration of PdNPs-PVP-Q in the culture media. Thus, further measurements of PdNPs-PVP-Q and quercetin in cellular compartments are required.
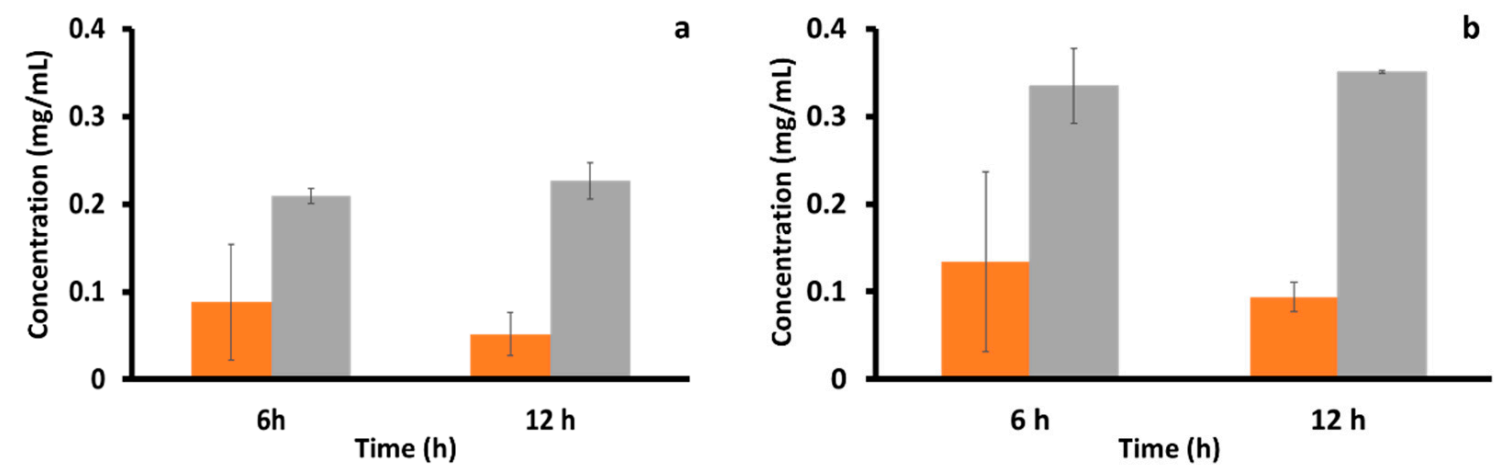

Figure 7. Quercetin liberation at different $\mathrm{pH}$. (a) $\mathrm{pH} 6.5$ and (b) $\mathrm{pH} 7.5$. 

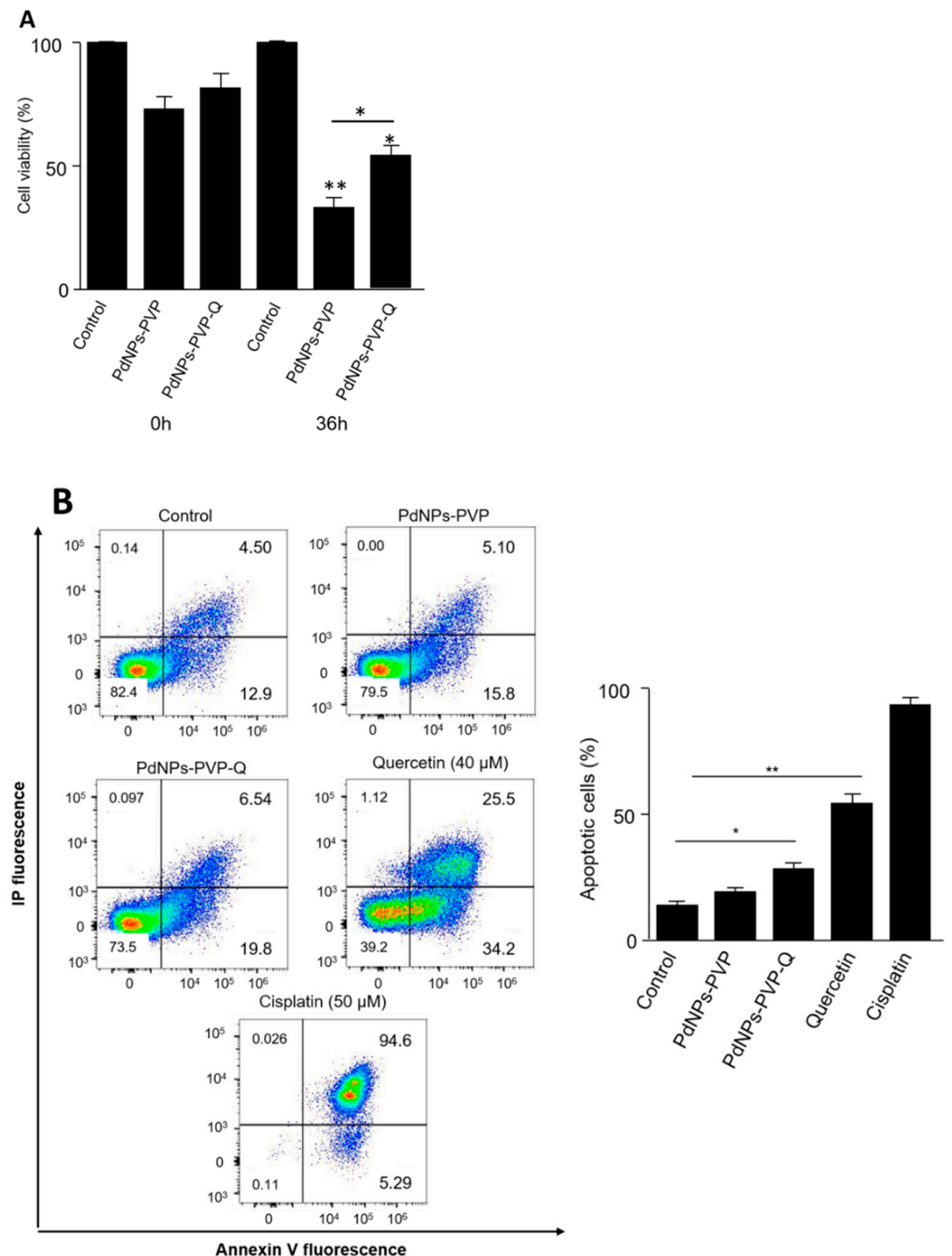

Figure 8. PdNPs-PVP-Q effects in HCT-15 cancer cells. (A). Cell proliferation assays were evaluated by MTT experiments. (B). Effect of PdNPs-PVP-Q on cell death. Graphs show the distribution of cell populations stained with Annexin-V and iodide propidium (IP) and sorted by flow cytometry. All assays were done in triplicate. Significance differences were indicated by ${ }^{*} p<0.05$ and ${ }^{* *} p<0.005$.

\section{Conclusions}

Here we report the successful development of novel PdNPs-PVP nanoparticles coupled to quercetin. The addition of quercetin to PdNPs-PVP was confirmed using UV/Vis and FT-IR spectrometry. Our data indicate that PdNPs-PVP-Q showed the smallest primary size, as well as the smallest hydrodynamic size and zeta potential than PdNPs or PdNPsPVP. Furthermore, PdNPs-PVP-Q showed catalytic activity in the degradation of $4 \mathrm{~N}$ and $\mathrm{MO}$, but not for $\mathrm{BM}$. In addition, we provide data indicating that quercetin liberation from PdNPs-PVP-Q was more efficient at a pH of 7.5, which is close to physiological pH (7.4), but no differences in quercetin liberation at 12 and $24 \mathrm{~h}$ were found. Additionally, significant differences in cell viability were observed in HCT-15 cells incubated with PdNPs-PVP or 
PdNPs-PVP-Q after $36 \mathrm{~h}$. We also found that PdNPs-PVP-Q induced apoptosis of HCT-15 cells at $36 \mathrm{~h}$ relative to the control, suggesting a potential antitumoral effect in vitro. We are aware of the limitation of our study, as we observed that PdNPs-PVP-Q induced only a small increase $(8 \%)$ in apoptosis of colorectal cancer cells relative to control, which may be due to the experimental conditions tested here which influenced the effective concentration of quercetin delivered in the cellular cytoplasm and the effect of temperature in the release of quercetin from PdNPs-PVP in the cellular microenvironment. Additionally, we did not discard the potential agglomeration of PdNPs-PVP-Q in the culture media and other unknown mechanisms involved in the cancer cell response to NDPs such as autophagy induction and cell cycle arrest. Therefore, further studies of PdNPs-PVP-Q and quercetin in cellular compartments are required to fully understand its utility in vitro and in vivo. In conclusion, the result of this study reveals that PdNPs-PVP may be used as a carrier of molecules with biological activity such as quercetin. Further studies are needed to increase the quercetin liberation from PdNPs-PVP and to use these palladium-based nanoparticles as carriers for different therapeutic molecules in cancer and other human diseases.

Author Contributions: Conceptualization, H.A.P.-C. and E.O.-B.; methodology, H.A.P.-C., and R.M.C.; formal analysis, H.A.P.-C., Y.M.S.-V., C.L.-C.; investigation R.M.-C., Y.M.S.-V., C.L.-C.; resources, L.A.M.-N., R.R.-M., E.O.-B.; writing—original draft preparation, H.A.P.-C.; writing-review and editing, E.O.-B., R.R.-M., C.L.-C., L.A.M.-N., L.N.M.-C., H.A.P.-C., R.M.-C.; visualization, H.A.P.-C., R.M.-C.; supervision, E.O.-B.; project administration, H.A.P.-C., E.O.-B.; funding acquisition, R.R.-M., and E.O.-B. All authors have read and agreed to the published version of the manuscript.

Funding: This research was funded by Consejo Nacional de Ciencia y Tecnología (CONACYT) and Ecos Nord grant number 263456; CONACYT grant number CB-258569 and Subsecretaría de Educación Superior (PRODEP) grant number 31606-UACH-CA-137.

Institutional Review Board Statement: Not applicable.

Informed Consent Statement: Not applicable.

Data Availability Statement: Not applicable.

Acknowledgments: We want to thank you for the support for the sample analysis to Daniel Lardizábal Gutiérrez from Centro de Investigación en Materiales Avanzados, S. C. (CIMAV) Chihuahua, Mexico.

Conflicts of Interest: The authors declare no conflict of interest. The funders had no role in the design of the study; in the collection, analyses, or interpretation of data; in the writing of the manuscript, or in the decision to publish the results.

\section{References}

1. Roy, S.; Ghosh, C.K.; Chandan, K.S. Nanotechnology; Taylor \& Francis: Boca Raton, FL, USA, 2018; ISBN 9781138032736.

2. Peigneux, A.; Oltolina, F.; Colangelo, D.; Iglesias, G.R.; Delgado, A.V.; Prat, M.; Jimenez-Lopez, C. Functionalized Biomimetic Magnetic Nanoparticles as Effective Nanocarriers for Targeted Chemotherapy. Part. Part. Syst. Charact. 2019, 36, 1-11. [CrossRef]

3. Abdifetah, O.; Na-Bangchang, K. Pharmacokinetic studies of nanoparticles as a delivery system for conventional drugs and herb-derived compounds for cancer therapy: A systematic review. Int. J. Nanomed. 2019, 14, 5659-5677. [CrossRef]

4. de Almeida, J.M.F.; Júnior, E.D.; Verríssimo, L.M.; Fernandes, N.S. pH-Dependent release system of isoniazid carried on nanoparticles of silica obtained from expanded perlite. Appl. Surf. Sci. 2019, 489, 297-312. [CrossRef]

5. Karimi, M.; Eslami, M.; Sahandi-Zangabad, P.; Mirab, F.; Farajisafiloo, N.; Shafaei, Z.; Ghosh, D.; Bozorgomid, M.; Dashkhaneh, F.; Hamblin, M.R. pH-Sensitive stimulus-responsive nanocarriers for targeted delivery of therapeutic agents. Wiley Interdiscip. Rev. Nanomed. Nanobiotechnology 2016, 8, 696-716. [CrossRef]

6. Rolim, W.R.; Pieretti, J.C.; Renó, D.L.S.; Lima, B.A.; Nascimento, M.H.M.; Ambrosio, F.N.; Lombello, C.B.; Brocchi, M.; De Souza, A.C.S.; Seabra, A.B. Antimicrobial Activity and Cytotoxicity to Tumor Cells of Nitric Oxide Donor and Silver Nanoparticles Containing PVA/PEG Films for Topical Applications. ACS Appl. Mater. Interfaces 2019. [CrossRef]

7. Ullah, S.; Ahmad, A.; Khan, A.; Zhang, J.; Raza, M.; ur Rahman, A.; Tariq, M.; Ali khan, U.; Zada, S.; Yuan, Q. Palladium nanoparticles synthesis, characterization using glucosamine as the reductant and stabilizing agent to explore their antibacterial \& catalytic applications. Microb. Pathog. 2018, 125, 150-157. [CrossRef]

8. Mahmoodi, S.; Elmi, A.; Hallaj-nezhadi, S. Copper Nanoparticles as Antibacterial Agents. J. Mol. Pharm. Org. Process Res. 2018, 6, 1-7. [CrossRef] 
9. Lorenzen, A.L.; Rossi, T.S.; Riegel-Vidotti, I.C.; Vidotti, M. Influence of cationic and anionic micelles in the (sono) chemical synthesis of stable $\mathrm{Ni}(\mathrm{OH}) 2$ nanoparticles: "In situ" zeta-potential measurements and electrochemical properties. Appl. Surf. Sci. 2018, 455, 357-366. [CrossRef]

10. Ching, Y.C.; Gunathilake, T.M.S.U.; Chuah, C.H.; Ching, K.Y.; Singh, R.; Liou, N.S. Curcumin/Tween 20-incorporated cellulose nanoparticles with enhanced curcumin solubility for nano-drug delivery: Characterization and in vitro evaluation. Cellulose 2019, 26, 5467-5481. [CrossRef]

11. Yan, B.; Wang, Y.; Ma, Y.; Zhao, J.; Liu, Y.; Wang, L. In vitro and in vivo evaluation of poly (acrylic acid) modified mesoporous silica nanoparticles as $\mathrm{pH}$ response carrier for $\beta$-elemene self-micro emulsifying. Int. J. Pharm. 2019, 572, 118768. [CrossRef]

12. Pisárčik, M.; Lukáč, M.; Jampílek, J.; Bilka, F.; Bilková, A.; Pašková, L'.; Devínsky, F.; Horáková, R.; Opravil, T. Silver nanoparticles stabilised with cationic single-chain surfactants. Structure-physical properties-biological activity relationship study. J. Mol. Liq. 2018, 272, 60-72. [CrossRef]

13. Yeap, S.P. Permanent agglomerates in powdered nanoparticles: Formation and future prospects. Powder Technol. 2018, 323, 51-59. [CrossRef]

14. Ko, Y.; Kim, J.; Lee, K.; Park, J.; Baik, Y.; Choi, H.; Lee, W. ScienceDirect Palladium nanoparticles from surfactant/fast- reduction combination one-pot synthesis for the liquid fuel cell applications. Int. J. Hydrog. Energy 2018, 43, 19029-19037. [CrossRef]

15. Nguyen, H.T.; Soe, Z.C.; Yang, K.Y.; Phung, C.D.; Nguyen, L.T.T.; Jeong, J.H.; Jin, S.G.; Choi, H.G.; Ku, S.K.; Yong, C.S.; et al. Transferrin-conjugated $\mathrm{pH}$-sensitive platform for effective delivery of porous palladium nanoparticles and paclitaxel in cancer treatment. Colloids Surf. B Biointerfaces 2019, 176, 265-275. [CrossRef]

16. Phan, T.T.V.; Hoang, G.; Nguyen, V.T.; Nguyen, T.P.; Kim, H.H.; Mondal, S.; Manivasagan, P.; Moorthy, M.S.; Lee, K.D.; Junghwan, O. Chitosan as a stabilizer and size-control agent for synthesis of porous flower-shaped palladium nanoparticles and their applications on photo-based therapies. Carbohydr. Polym. 2019, 205, 340-352. [CrossRef]

17. Sharmila, G.; Farzana Fathima, M.; Haries, S.; Geetha, S.; Manoj Kumar, N.; Muthukumaran, C. Green synthesis, characterization and antibacterial efficacy of palladium nanoparticles synthesized using Filicium decipiens leaf extract. J. Mol. Struct. 2017, 1138, 35-40. [CrossRef]

18. Athie-García, M.S.; Piñón-Castillo, H.A.; Muñoz-Castellanos, L.N.; Ulloa-Ogaz, A.L.; Martínez-Varela, P.I.; Quintero-Ramos, A.; Duran, R.; Murillo-Ramirez, J.G.; Orrantia-Borunda, E. Cell wall damage and oxidative stress in Candida albicans ATCC10231 and Aspergillus niger caused by palladium nanoparticles. Toxicol. Vitr. 2018, 48. [CrossRef]

19. Nisar, P.; Ali, N.; Rahman, L.; Ali, M.; Shinwari, Z.K. Antimicrobial activities of biologically synthesized metal nanoparticles: An insight into the mechanism of action. J. Biol. Inorg. Chem. 2019, 24, 929-941. [CrossRef]

20. Hamdouche, Y.; Guehi, T.; Durand, N.; Kedjebo, K.B.D.; Montet, D.; Meile, J.C. Dynamics of microbial ecology during cocoa fermentation and drying: Towards the identification of molecular markers. Food Control 2015, 48, 117-122. [CrossRef]

21. Tahir, K.; Nazir, S.; Li, B.; Ahmad, A.; Nasir, T.; Khan, A.U.; Shah, S.A.A.; Khan, Z.U.H.; Yasin, G.; Hameed, M.U. Sapium sebiferum leaf extract mediated synthesis of palladium nanoparticles and in vitro investigation of their bacterial and photocatalytic activities. J. Photochem. Photobiol. B Biol. 2016, 164, 164-173. [CrossRef]

22. Ocsoy, I.; Demirbas, A.; McLamore, E.S.; Altinsoy, B.; Ildiz, N.; Baldemir, A. Green synthesis with incorporated hydrothermal approaches for silver nanoparticles formation and enhanced antimicrobial activity against bacterial and fungal pathogens. J. Mol. Liq. 2017, 238, 263-269. [CrossRef]

23. Ildiz, N.; Baldemir, A.; Altinkaynak, C.; Özdemir, N.; Yilmaz, V.; Ocsoy, I. Self assembled snowball-like hybrid nanostructures comprising Viburnum opulus L. extract and metal ions for antimicrobial and catalytic applications. Enzyme Microb. Technol. 2017, 102, 60-66.

24. Li, T.; Li, F.; Liu, X.; Liu, J.; Li, D. Synergistic anti-inflammatory effects of quercetin and catechin via inhibiting activation of TLR4-MyD88-mediated NF-kB and MAPK signaling pathways. Phyther. Res. 2019, 33, 756-767. [CrossRef]

25. Reyes-Farias, M.; Carrasco-Pozo, C. The anti-cancer effect of quercetin: Molecular implications in cancer metabolism. Int. J. Mol. Sci. 2019, 20, 1-19. [CrossRef]

26. Ezzati, M.; Yousefi, B.; Velaei, K.; Safa, A. A review on anti-cancer properties of Quercetin in breast cancer. Life Sci. 2020, 248. [CrossRef]

27. Kashyap, D.; Garg, V.K.; Tuli, H.S.; Yerer, M.B.; Sak, K.; Sharma, A.K.; Kumar, M.; Aggarwal, V.; Sandhu, S.S. Fisetin and quercetin: Promising flavonoids with chemopreventive potential. Biomolecules 2019, 9, 174.

28. Boonlaos, A.; Wechsirisan, W.; Chaibuth, P.; Chupia, V. Comparative Immunology, Microbiology and Infectious Diseases Quercetin enhances and modulates the fungal killing efficacy of chicken heterophils through immunological recognition, effector functions, and resolution. Comp. Immunol. Microbiol. Infect. Dis. 2021, 74, 101582. [CrossRef]

29. Tang, S.; Deng, X.; Zhou, J.; Li, Q.; Ge, X.; Miao, L. Biomedicine \& Pharmacotherapy Pharmacological basis and new insights of quercetin action in respect to its anti-cancer effects. Biomed. Pharmacother. 2020, 121, 109604. [CrossRef]

30. Liu, Y.; Tang, Z.; Lin, Y.; Qu, X.; Lv, W.; Wang, G.; Li, C. ScienceDirect Effects of quercetin on proliferation and migration of human glioblastoma U251 cells. Biomed. Pharmacother. 2017, 92, 33-38. [CrossRef]

31. Teekaraman, D.; Elayapillai, S.P.; Viswanathan, M.P.; Jagadeesan, A. Chemico-Biological Interactions Quercetin inhibits human metastatic ovarian cancer cell growth and modulates components of the intrinsic apoptotic pathway in PA-1 cell line. Chem. Biol. Interact. 2019, 300, 91-100. [CrossRef] 
32. Aalinkeel, R.; Bindukumar, B.; Reynolds, J.L.; Sykes, D.E.; Mahajan, S.D.; Chadha, K.C.; Schwartz, S.A. The Dietary Bioflavonoid, Quercetin, Selectively Induces Apoptosis of Prostate Cancer Cells by Down-Regulating the Expression of Heat Shock Protein 90. Prostate 2008, 1789. [CrossRef]

33. Nguyen, H.T.; Goycoolea, F.M. Chitosan/Cyclodextrin/TPP nanoparticles loaded with quercetin as novel bacterial quorum sensing inhibitors. Molecules 2017, 22, 1-24. [CrossRef]

34. Liu, H.; Han, Y.; Wang, T.; Zhang, H.; Xu, Q.; Yuan, J.; Li, Z. Targeting Microglia for Therapy of Parkinson's Disease by Using Biomimetic Ultrasmall Nanoparticles. J. Am. Chem. Soc. 2020, 142, 21730-21742. [CrossRef]

35. Gurunathan, S.; Jeyaraj, M.; Kang, M.H.; Kim, J.H. Melatonin enhances palladium-nanoparticle-induced cytotoxicity and apoptosis in human lung epithelial adenocarcinoma cells a549 and h1229. Antioxidants 2020, 9, 1-29. [CrossRef]

36. Fleming, E.; Luo, Y. Co-delivery of synergistic antioxidants from food sources for the prevention of oxidative stress. J. Agric. Food Res. 2021, 3, 100107. [CrossRef]

37. Balakrishnan, S.; Bhat, F.A.; Raja Singh, P.; Mukherjee, S.; Elumalai, P.; Das, S.; Patra, C.R.; Arunakaran, J. Gold nanoparticleconjugated quercetin inhibits epithelial-mesenchymal transition, angiogenesis and invasiveness via EGFR/VEGFR-2-mediated pathway in breast cancer. Cell Prolif. 2016, 49, 678-697. [CrossRef]

38. de Oliveira Pedro, R.; Hoffmann, S.; Pereira, S.; Goycoolea, F.M.; Schmitt, C.C.; Neumann, M.G. Self-assembled amphiphilic chitosan nanoparticles for quercetin delivery to breast cancer cells. Eur. J. Pharm. Biopharm. 2018, 131, 203-210. [CrossRef]

39. Sun, D.; Li, N.; Zhang, W.; Zhao, Z.; Mou, Z.; Huang, D.; Liu, J.; Wang, W. Design of PLGA-functionalized quercetin nanoparticles for potential use in Alzheimer's disease. Colloids Surfaces B Biointerfaces 2016, 148, 116-129. [CrossRef]

40. Creighton, J.A.; Eadon, D.G. Ultraviolet-visible absorption spectra of the colloidal metallic elements. J. Chem. Soc. Faraday Trans. 1991, 87, 3881-3891. [CrossRef]

41. Li, G.; Li, Y.; Wang, Z.; Liu, H. Green synthesis of palladium nanoparticles with carboxymethyl cellulose for degradation of azo-dyes. Mater. Chem. Phys. 2017, 187, 133-140. [CrossRef]

42. Xiong, Y.; Huang, L.; Mahmud, S.; Yang, F.; Liu, H. Bio-synthesized palladium nanoparticles using alginate for catalytic degradation of azo-dyes. Chin. J. Chem. Eng. 2020, 28, 1334-1343. [CrossRef]

43. Nasrollahzadeh, M.; Mohammad Sajadi, S. Pd nanoparticles synthesized in situ with the use of Euphorbia granulate leaf extract: Catalytic properties of the resulting particles. J. Colloid Interface Sci. 2016, 462, 243-251. [CrossRef]

44. Yang, Y.; Wang, T.; Chen, D.; Ma, Q.; Zheng, Y.; Liao, S.; Wang, Y.; Zhang, J. Quercetin preferentially induces apoptosis in KRAS-mutant colorectal cancer cells via JNK signaling pathways. Cell Biol. Int. 2019, 43, 117-124. [CrossRef]

45. Walbrück, K.; Kuellmer, F.; Witzleben, S.; Guenther, K. Synthesis and characterization of PVP-stabilized palladium nanoparticles by XRD, SAXS, SP-ICP-MS, and SEM. J. Nanomater. 2019, 2019. [CrossRef]

46. Çelik, B.; Yildiz, Y.; Sert, H.; Erken, E.; Koşkun, Y.; Şen, F. Monodispersed palladium-cobalt alloy nanoparticles assembled on poly(N-vinyl-pyrrolidone) (PVP) as a highly effective catalyst for dimethylamine borane (DMAB) dehydrocoupling. RSC Adv. 2016, 6, 24097-24102. [CrossRef]

47. Rashidian Vaziri, M.R.; Omidvar, A.; Jaleh, B.; Partovi Shabestari, N. Investigating the extrinsic size effect of palladium and gold spherical nanoparticles. Opt. Mater. (Amst) 2017, 64, 413-420. [CrossRef]

48. Wu, Z.; Xiao, D.; Lee, J.; Ren, P.; Song, M.; Li, D. Palladium nanostructures with well-controlled morphologies obtained by one-pot and one-step polyol method. J. Cryst. Growth 2019, 521, 34-40. [CrossRef]

49. Yang, L.; Cheng, G.; Guo, Y.; Li, D.; Xia, L.; Liu, H. Steam treatment: A facile and effective process for the removal of PVP from shape-controlled palladium nanoparticles. Nanoscale 2018, 10, 11992-11996. [CrossRef]

50. Ramalingam, V.; Raja, S.; Harshavardhan, M. In situ one-step synthesis of polymer-functionalized palladium nanoparticles: An efficient anticancer agent against breast cancer. Dalt. Trans. 2020, 49, 3510-3518. [CrossRef]

51. Nasrollahzadeh, M.; Sajadi, S. Green synthesis of copper nanoparticles using Ginkgo biloba L. leaf extract and their catalytic activity for the Huisgen cycloaddition of azides and alkynes at. J. Colloid Interface Sci. 2015, 457, 141-147.

52. Garai, C.; Hasan, S.N.; Barai, A.C.; Ghorai, S.; Panja, S.K.; Bag, B.G. Green synthesis of Terminalia arjuna-conjugated palladium nanoparticles (TA-PdNPs) and its catalytic applications. J. Nanostructure Chem. 2018, 8, 465-472. [CrossRef]

53. Le, N.T.T.; Nguyen, D.H.; Nguyen, N.H.; Ching, Y.C.; Nguyen, D.Y.P.; Ngo, C.Q.; Nhat, H.N.T.; Thi, T.T.H. Silver nanoparticles ecofriendly synthesized by achyranthes aspera and scoparia dulcis leaf broth as an effective fungicide. Appl. Sci. 2020, 10, 1-14. [CrossRef]

54. Givens, B.E.; Wilson, E.; Fiegel, J. The effect of salts in aqueous media on the formation of the BSA corona on SiO 2 nanoparticles Colloids Surfaces B Biointerfaces 2019, 179, 374-381. [CrossRef]

55. Iyahraja, S.; Rajadurai, J.S. Stability of Aqueous Nanofluids Containing PVP-Coated Silver Nanoparticles. Arab. J. Sci. Eng. 2016, 41, 653-660. [CrossRef]

56. Saxena, M.; Tarachand Sathe, V.G.; Okram, G.S. Enhanced zeta potential of polyol method synthesized PVP-capped Sb 2 S 3 nanoparticles. AIP Conf. Proc. 2019, 2100, 2-7. [CrossRef]

57. Tarachand, Sathe, V.G.; Okram, G.S. G.; Okram, G.S. Zeta potential and Raman studies of PVP capped Bi2S3 nanoparticles synthesized by polyol method. AIP Conf. Proc. 2018, 1953, 3-7. [CrossRef]

58. Vergara-Castañeda, H.; Hernandez-Martinez, A.R.; Estevez, M.; Mendoza, S.; Luna-Barcenas, G.; Pool, H. Quercetin conjugated silica particles as novel biofunctional hybrid materials for biological applications. J. Colloid Interface Sci. 2016, 466, 44-55. [CrossRef] 
59. Lebaschi, S.; Hekmati, M.; Veisi, H. Green synthesis of palladium nanoparticles mediated by black tea leaves (Camellia sinensis) extract: Catalytic activity in the reduction of 4-nitrophenol and Suzuki-Miyaura coupling reaction under ligand-free conditions. J. Colloid Interface Sci. 2017, 485, 223-231. [CrossRef]

60. Sunoqrot, S.; Al-Shalabi, E.; Messersmith, P.B. Facile synthesis and surface modification of bioinspired nanoparticles from quercetin for drug delivery. Biomater. Sci. 2018, 6, 2656-2666. [CrossRef]

61. Larkin, P. IR and Raman Spectroscopy; Elsevier: Amsterdam, The Netherlands, 2011; ISBN 978-0-12-386984-5.

62. Sadhukhan, P.; Kundu, M.; Chatterjee, S.; Ghosh, N.; Manna, P.; Das, J.; Sil, P.C. Targeted delivery of quercetin via pH-responsive zinc oxide nanoparticles for breast cancer therapy. Mater. Sci. Eng. C 2019, 100, 129-140. [CrossRef]

63. Seo, M.H.; Choi, S.M.; Lee, D.U.; Kim, W.B.; Chen, Z. Correlation between theoretical descriptor and catalytic oxygen reduction activity of graphene supported palladium and palladium alloy electrocatalysts. J. Power Sources 2015, 300, 1-9. [CrossRef]

64. Anjum, F.; Khan, M.I.; Khan, M.A. Efficient synthesis of palladium nanoparticles using guar gum as stabilizer their applications as catalyst in reduction reactions and degradation of azo dyes. Green Process Synth 2020, 63-76.

65. Rigas, F.; Morales, A.A.; Navarrete, M. Assessment of Copper Slag as a Sustainable Fenton-Type Photocatalyst for Water Disinfection. Water Reclam. Sustain. 2014, 199-227. [CrossRef]

66. Peskova, M.; Ilkovics, L.; Hynek, D.; Dostalova, S.; Sanchez-Carnerero, E.M.; Remes, M.; Heger, Z.; Pekarik, V. Detergent-modified catalytic and enzymomimetic activity of silver and palladium nanoparticles biotemplated by Pyrococcus furiosus ferritin. $J$. Colloid Interface Sci. 2019, 537, 20-27. [CrossRef]

67. Pourreza, N.; Abdollahzadeh, R. Colorimetric determination of hydrazine and nitrite using catalytic effect of palladium nanoparticles on the reduction reaction of methylene blue. Microchem. J. 2019, 150, 104067. [CrossRef]

68. Chatha, S.A.S.; Asgher, M.; Iqbal, H.M.N. Enzyme-based solutions for textile processing and dye contaminant biodegradation-a review. Environ. Sci. Pollut. Res. 2017, 24, 14005-14018. [CrossRef]

69. Raman, C.D.; Kanmani, S. Decolorization of Mono Azo Dye and Textile Wastewater using Nano Iron Particles. Environ. Prog. Sustain. Energy 2019, 38, S366-S376. [CrossRef]

70. McNamara, K.; Tofail, S.A.M. Nanosystems: The use of nanoalloys, metallic, bimetallic, and magnetic nanoparticles in biomedical applications. Phys. Chem. Chem. Phys. 2015, 17, 27981-27995. [CrossRef]

71. Wu, C.Y.; Chen, Y.C. Riboflavin immobilized $\mathrm{Fe}_{3} \mathrm{O}_{4}$ magnetic nanoparticles carried with n-butylidenephthalide as targeting-based anticancer agents. Artif. Cells, Nanomedicine Biotechnol. 2019, 47, 210-220. [CrossRef]

72. Fan, X.; Domszy, R.C.; Hu, N.; Yang, A.J.; Yang, J.; David, A.E. Synthesis of silica-alginate nanoparticles and their potential application as pH-responsive drug carriers. J. Sol-Gel Sci. Technol. 2019, 91, 11-20. [CrossRef]

73. Akal, Z.U.; Alpsoy, L.; Baykal, A. Superparamagnetic iron oxide conjugated with folic acid and carboxylated quercetin for chemotherapy applications. Ceram. Int. 2016, 42, 9065-9072. [CrossRef]

74. Baksi, R.; Singh, D.P.; Borse, S.P.; Rana, R.; Sharma, V.; Nivsarkar, M. In vitro and in vivo anticancer efficacy potential of Quercetin loaded polymeric nanoparticles. Biomed. Pharmacother. 2018, 106, 1513-1526. [CrossRef]

75. Gurunathan, S.; Qasim, M.; Park, C.H.; Iqbal, M.A.; Yoo, H.; Hwang, J.H.; Uhm, S.J.; Song, H.; Park, C.; Choi, Y.; et al. Cytotoxicity and transcriptomic analyses of biogenic palladium nanoparticles in human ovarian cancer cells (Skov3). Nanomaterials 2019, 9. [CrossRef]

76. Chong, Y.; Dai, X.; Fang, G.; Wu, R.; Zhao, L.; Ma, X.; Tian, X.; Lee, S.; Zhang, C.; Chen, C.; et al. Palladium concave nanocrystals with high-index facets accelerate ascorbate oxidation in cancer treatment. Nat. Commun. 2018, 9, 1-11. [CrossRef]

77. De Mello Costa, A.R.; Marquiafável, F.S.; De Oliveira Lima Leite Vaz, M.M.; Rocha, B.A.; Pires Bueno, P.C.; Amaral, P.L.M.; Da Silva Barud, H.; Berreta-Silva, A.A. Quercetin-PVP K25 solid dispersions: Preparation, thermal characterization and antioxidant activity. J. Therm. Anal. Calorim. 2011, 104, 273-278. [CrossRef]

78. Vittorio, O.; Curcio, M.; Cojoc, M.; Goya, G.F.; Hampel, S.; Iemma, F.; Dubrovska, A.; Cirillo, G. Polyphenols delivery by polymeric materials: Challenges in cancer treatment. Drug Deliv. 2017, 24, 162-180. [CrossRef] 